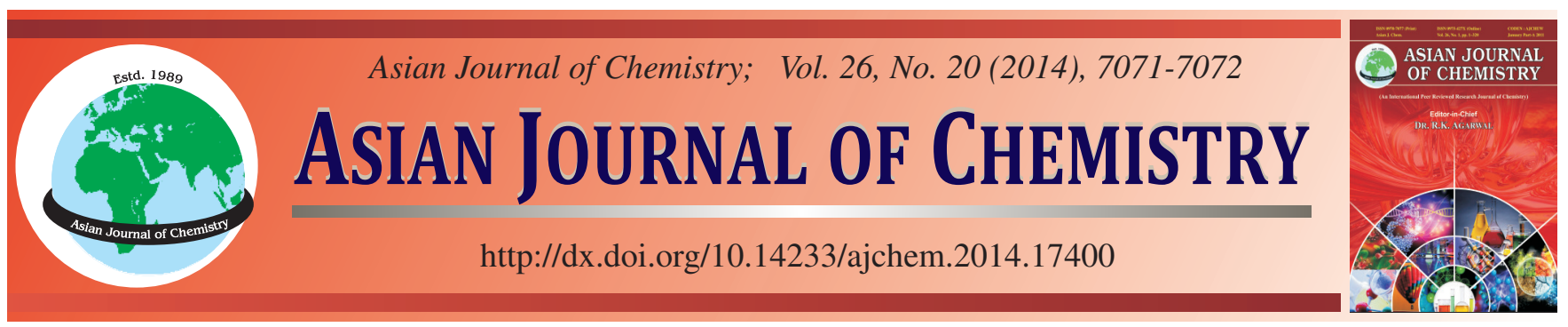

NOTE

\title{
Cobalt(II) Coordination Polymers with Three-Dimensional Supramolecular Structure Based on Flexible Dicarboxylate and Imidazole-Containing Ligands
}

\author{
YUJING WANG
}

Yucheng People's Hospital, Yucheng 251200, Shandong Province, P.R. China

Corresponding author: E-mail: whyull@yeah.net

A new coordination polymers $\left\{\left[\mathrm{Co}\left(2,4^{\prime}-\mathrm{opb}\right)(\mathrm{bimb})\right] \cdot \mathrm{H}_{2} \mathrm{O}\right\}_{\mathrm{n}}(\mathbf{1})\left(2,4^{\prime}-\mathrm{opb}=2\right.$-(4'-carboxy-phenoxy)benzoic acid, bimb $=1,4-$ bis $(1$-imidazolyl)-2,5-dimethyl benzene), has been prepared by hydrothermal synthesis. Complex $\left[\mathrm{Co}\left(2,4^{\prime} \text {-opb)(bimb) }\right]_{\mathrm{n}}(\mathbf{1})\right.$, is monoclinic, space group $\mathrm{P} 2{ }_{1} / \mathrm{c}$ with $\mathrm{a}=11.473$ (5) $\AA, \mathrm{b}=11.905$ (5) $\AA, \mathrm{c}=18.899$ (5) $\AA, \beta=100.872^{\circ} \mathrm{V}=2535.0(15) \AA^{3}, \mathrm{Z}=4, \mathrm{Mr}=571.44, \mathrm{D}_{\mathrm{c}}=1.497 \mathrm{~g} / \mathrm{cm}^{3}$, $\mathrm{F}(000)=1180$ and $\mu=0.73 \mathrm{~mm}^{-1}$. The final refinement gave $\mathrm{R}=0.0305$ and $w \mathrm{R}=0.0831$ for 5110 reflections with I $>2 \sigma$ (I). X-ray diffraction analysis reveals that complex 1 shows a three-dimensional supramolecular structure based on a two-dimensional $(4,4)$ sql layer.

Keywords: Cobalt(II), Coordination polymer, Imidazole.

Assembly of metal organic frameworks (MOFs) has been an important issue because of their intriguing structural versatility and their potential applications as functional crystalline materials in gas storage, separation, catalysis, sensor and drug delivery ${ }^{1-5}$. Crystal engineering using periodic networks as blueprints in the design and construction of extended porous frameworks has proved to be very fruitful, especially in the emerging discipline of reticular chemistry ${ }^{6-8}$.

In this we used the semirigid carboxylate and imidazolecontaining ligand to construct one new $\mathrm{Co}$ (II) coordination polymer.

Materials and physical measurements: All reagents and solvents employed were commercially available and used without further purification. Elemental analysis was carried out on a Carlo Erba 1106 full-automatic trace organic elemental analyzer.

\section{Synthesis}

Synthesis of $\left\{\left[\mathrm{Co}\left(2,4^{\prime}-\mathrm{opb}\right)(\operatorname{bimb})\right] \cdot \mathrm{H}_{2} \mathrm{O}\right\}_{\mathrm{n}}(\mathbf{1})$ : The mixtures of $\mathrm{CoCl}_{2} \cdot 6 \mathrm{H}_{2} \mathrm{O}(0.5 \mathrm{mmol}, 0.119 \mathrm{~g}), 2,4^{\prime}-\mathrm{opb}(0.5$ mmol, $0.129 \mathrm{~g})$, bimb (0.5 mmol, $0.119 \mathrm{~g}), \mathrm{NaOH}$ (1 mmol, $0.04 \mathrm{~g}$ ) and $12 \mathrm{~mL}$ of water were heated to $140{ }^{\circ} \mathrm{C}$ for 3 days and then cooled to room-temperature. The red crystals were obtained in pure phase, washed with water and ethanol and dried at room temperature (Yield: $43 \%$ based on $\mathrm{Co}$ ). Elemental Anal. Calcd. (\%) for $\mathrm{C}_{28} \mathrm{H}_{24} \mathrm{~N}_{4} \mathrm{O}_{6} \mathrm{Co}$ : C, 58.85; $\mathrm{H}$, 4.23 ; N, 9.80. Found: C, 58.54; H, 4.23; N, 9.81.
X-ray crystallography: Single crystal X-ray diffraction analyses of complex $\mathbf{1}$ was carried out on a Bruker SMART APEX-II CCD diffractometer equipped with a graphite monochromated $\mathrm{MoK}_{\alpha}$ radiation $(\lambda=0.71073 \AA$ ) by using a $\omega$-scan mode. Empirical absorption correction was applied using the SADABS programs ${ }^{9}$. All the structures were solved by direct methods and refined by full-matrix least-squares methods on $\mathrm{F}^{2}$ using the program ${ }^{10}$ SHEXL 97 . All non-hydrogen atoms were refined anisotropically. The hydrogen atoms were located by geometrically calculations and their positions and thermal parameters were fixed during the structure refinement. The selected bond lengths and angles are listed in Table-1.

\begin{tabular}{llll}
\multicolumn{4}{c}{ TABLE-1 } \\
SELECTED BOND LENGTHS $(\AA)$ \\
AND ANGLES $\left({ }^{\circ}\right)$ FOR COMPLEXES 1 \\
\hline \multicolumn{4}{c}{ Complex 1 } \\
\hline $\mathrm{Co}(1)-\mathrm{O}(1)$ & $1.9820(16)$ & $\mathrm{Co}(1)-\mathrm{N}(3)$ & $2.0184(14)$ \\
$\mathrm{Co}(1)-\mathrm{O}(5)^{\mathrm{i}}$ & $2.0097(14)$ & $\mathrm{Co}(1)-\mathrm{N}(1)$ & $2.0522(14)$ \\
$\mathrm{O}(1)-\mathrm{Co}(1)-\mathrm{O}(5)^{\mathrm{I}}$ & $101.87(5)$ & $\mathrm{O}(5)^{\mathrm{i}}-\mathrm{Co}(1)-\mathrm{N}(1)$ & $101.48(5)$ \\
$\mathrm{O}(1)-\mathrm{Co}(1)-\mathrm{N}(3)$ & $126.13(6)$ & $\mathrm{N}(3)-\mathrm{Co}(1)-\mathrm{N}(1)$ & $109.65(6)$ \\
$\mathrm{O}(5)^{\mathrm{i}}-\mathrm{Co}(1)-\mathrm{N}(3)$ & $105.63(5)$ & $\mathrm{O}(1)-\mathrm{Co}(1)-\mathrm{N}(1)$ & $108.94(6)$ \\
\hline Symmetry code: (i) $\mathrm{x}-1, \mathrm{y}, \mathrm{z}$ &
\end{tabular}

Single-crystal X-ray diffraction analysis reveals that complex 2 crystallizes in the system, space group and exhibits a two-dimensional layer structure with sql topological net. As shown in Fig. 1, the Co(II) is coordinated by two carboxylate 
oxygen atoms and two nitrogen atoms in a tetrahedral geometry. The carboxylate ligand adopts bis-monodentate coordination mode, connecting the adjacent $\mathrm{Co}$ (II) ions into a one-dimensional chain. The 1D motifs are further extended by bimb spacers to result in a 2D network (Fig. 2). The organic ligands and metal ions can be viewed as linkers and nodes, thus, the 2D network can be simplified as a 2D sql topological net. The 2D layers stack in ABAB sequence (Fig. 3). The hydrogen bonds further connect the 2D layer structure to a $3 \mathrm{D}$ supramolecular structure (Fig. 4).

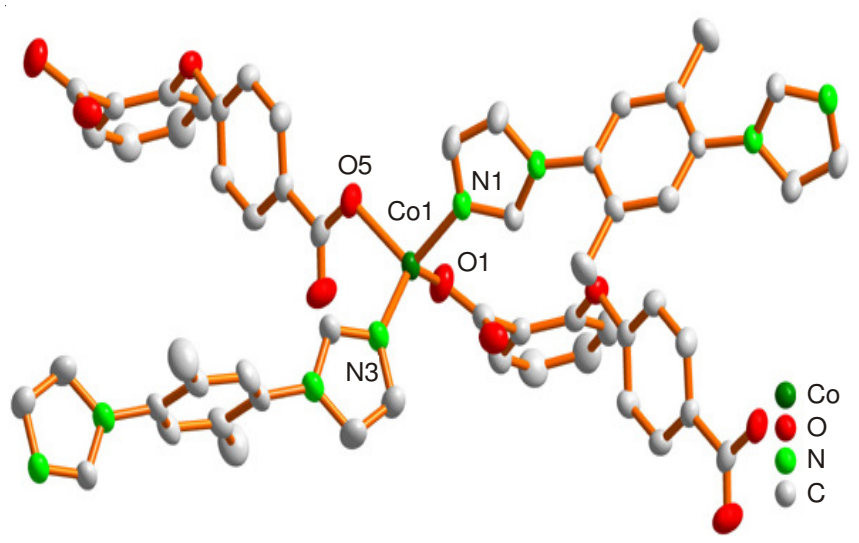

Fig. 1. Coordination environment for $\mathrm{Co}(\mathrm{II})$ ion

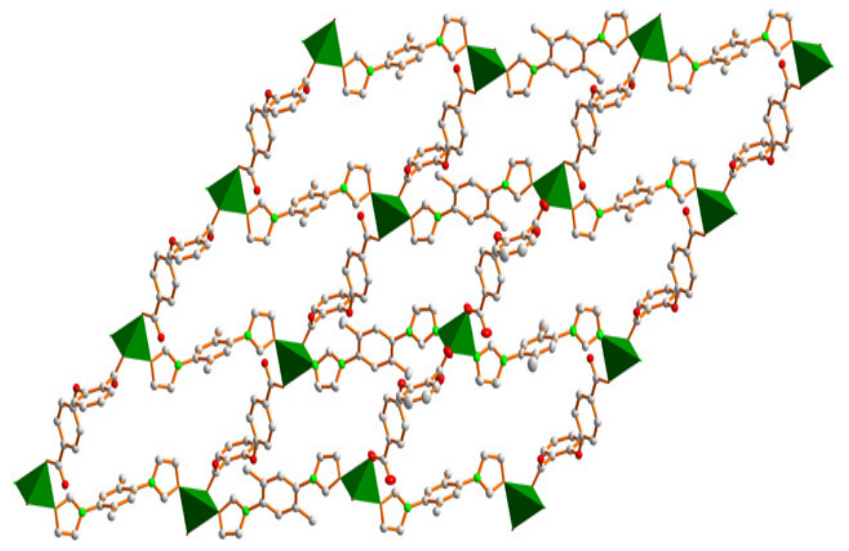

Fig. 2. 2D $(4,4)$ sql layer structure for complex $\mathbf{1}$

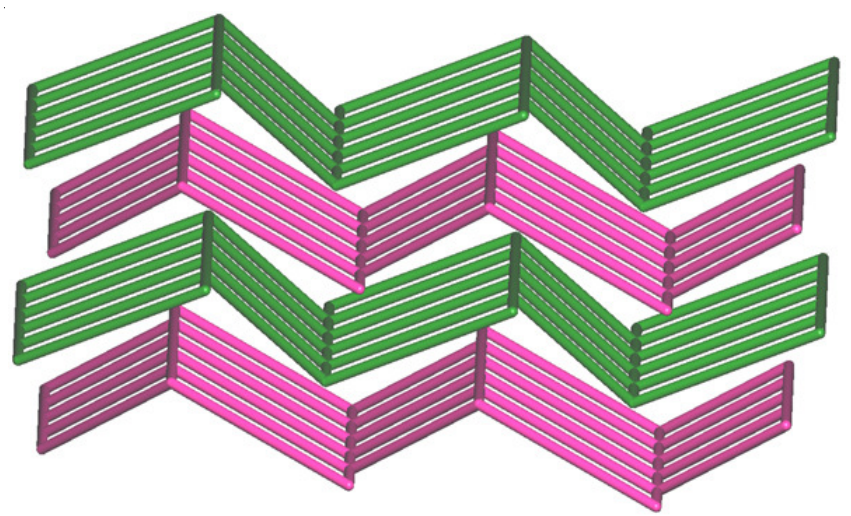

Fig. 3. ABAB packed style for complex 2

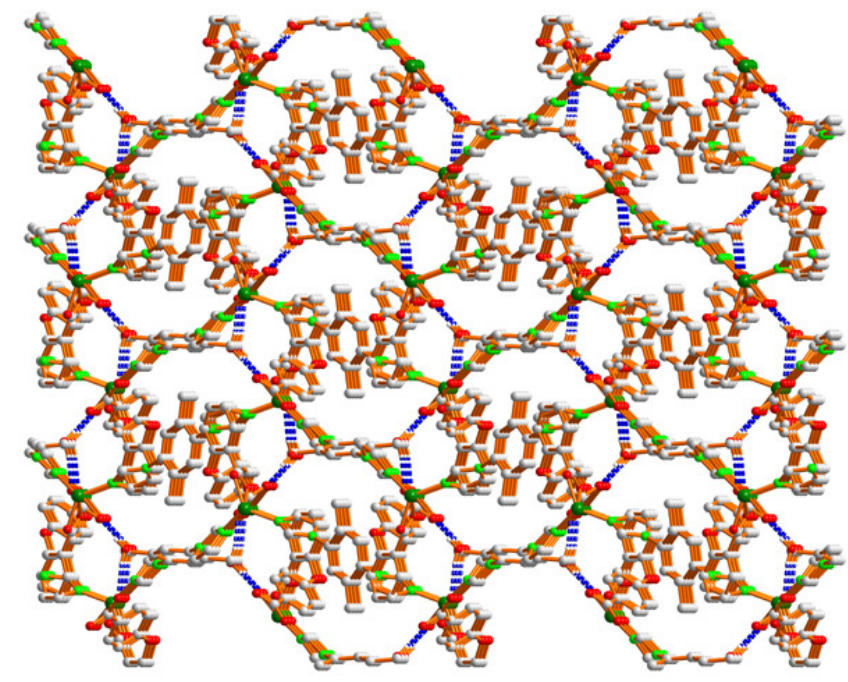

Fig. 4. 3D supramolecular structure for complex $\mathbf{1}$

\section{REFERENCES}

1. M. O'Keeffe and O.M. Yaghi, Chem. Rev., 112, 675 (2012).

2. K. Sumida, D.L. Rogow, J.A. Mason, T.M. McDonald, E.D. Bloch, Z.R. Herm, T.-H. Bae and J.R. Long, Chem. Rev., 112, 724 (2012).

3. J.-R. Li, J. Sculley and H.-C. Zhou, Chem. Rev., 112, 869 (2012).

4. L.E. Kreno, K. Leong, O.K. Farha, M. Allendorf, R.P. Van Duyne and J.T. Hupp, Chem. Rev., 112, 1105 (2012).

5. M. Yoon, R. Srirambalaji and K. Kim, Chem. Rev., 112, 1196 (2012).

6. P. Horcajada, R. Gref, T. Baati, P.K. Allan, G. Maurin, P. Couvreur, G. Férey, R.E. Morris and C. Serre, Chem. Rev., 112, 1232 (2012).

7. F.A. Almeida Paz, J. Klinowski, S.M.F. Vilela, J.P.C. Tomè, J.A.S. Cavaleiro and J. Rocha, J. Chem. Soc. Rev., 41, 1088 (2012).

8. O.M. Yaghi, M. O'Keeffe, N.W. Ockwig, H.K. Chae, M. Eddaoudi and J. Kim, Nature, 423, 705 (2003).

9. A.X.S. Bruker, SAINT Software Reference Manual, Madison, WI, (1998).

10. G.M. Sheldrick, SHELXTL NT Version 5.1. Program for Solution and Refinement of Crystal Structures, University of Göttingen, Germany (1997). 